\title{
Differences in the prescribing of medication for physical disorders in individuals with $v$. without mental illness: meta-analysis
}

\author{
Alex J. Mitchell, Oliver Lord and Darren Malone
}

\section{Background}

There is some concern that patients with mental illness may be in receipt of inferior medical care, including prescribed medication for medical conditions.

\section{Aims}

We aimed to quantify possible differences in the prescription of medication for medical conditions in those with $v$. without mental illness.

\section{Method}

Systematic review and random effects meta-analysis with a minimum of three independent studies to warrant pooling by drug class

\section{Results}

We found 61 comparative analyses (from 23 publications) relating to the prescription of 12 classes of medication for cardiovascular health, diabetes, cancer, arthritis, osteoporosis and HIV in a total sample of 1931509 people. In those with severe mental illness the adjusted odds ratio (OR) for an equitable prescription was 0.74 ( $95 \% \mathrm{Cl} 0.63-0.86)$, with lower than expected prescriptions for angiotensin-converting enzyme inhibitors or angiotensin II receptor blockers (ACE/ ARBS), beta-blockers and statins. People with affective disorder had an odds ratio of 0.75 ( $95 \% \mathrm{Cl} 0.55-1.02)$ but this was not significant. Individuals with a history of other (miscellaneous) mental illness had an odds ratio of 0.95 (95\% $\mathrm{Cl}$ 0.92-0.98) of comparable medication with lower receipt of ACE/ARBs but not highly active antiretroviral therapy (HAART) medication. Results were significant in both adjusted and unadjusted analyses.

\section{Conclusions}

Individuals with severe mental illness (including schizophrenia) appear to be prescribed significantly lower quantities of several common medications for medical disorders, largely for cardiovascular indications, although further work is required to clarify to what extent this is because of prescriber intent.

\section{Declaration of interest}

\section{None.}

National guidelines from several countries are agreed that the medical care of patients with mental disorders is of paramount importance. ${ }^{1-5}$ Yet, serious concerns have been raised about the quality of medical (and screening) services offered to patients with severe mental illness. ${ }^{6}$ Individuals with schizophrenia receive as little as half of the monitoring offered to people without schizophrenia in some studies. ${ }^{7}$ Further, there is evidence that people with severe mental illness receive suboptimal treatment for established medical conditions. ${ }^{8,9}$ These disparities in treatment exist in some of the most critical areas of patient care such as general medicine, cardiovascular and cancer care. ${ }^{10}$ This is particularly concerning given that people with schizophrenia appear to have higher rates of post-operative complications, ${ }^{11}$ higher post-operative mortality ${ }^{12}$ and higher than expected non-suicide-related mortality. ${ }^{13}$ Indeed, the physical health of individuals with severe mental illness is poorer than the general population. ${ }^{14,15}$ Looking at comorbidity in more detail shows that individuals with schizophrenia have higher rates of hypothyroidism, dermatitis, eczema, obesity, epilepsy, viral hepatitis, diabetes (type 2), essential hypertension, chronic obstructive pulmonary disease and fluid/electrolyte disorders. ${ }^{16,17}$ Patients with bipolar I disorder also have higher rates of arthritis, hypertension, gastritis, angina and stomach ulcer. ${ }^{18}$ The presence of these medical comorbidities adversely affects not just quality of life but also recovery from the underlying psychiatric disorder, ${ }^{19}$ length of hospital admissions ${ }^{20}$ and paradoxically the likelihood of being offered psychotropic medication. ${ }^{21}$

Patients with severe mental illness are also at risk of receiving less than adequate preventive services such as medical screening procedures. Medical screening is important not just for the reduction in future morbidity but also low receipt of preventive care is associated with lower quality of life. ${ }^{22}$ Lord et al recently reviewed studies that examined preventive care in individuals with $v$. without psychiatric illness. ${ }^{23}$ For those individuals with schizophrenia, eight of nine analyses showed inferior preventive care in several areas including in relation to osteoporosis screening, blood pressure monitoring, vaccinations, mammography and cholesterol monitoring. ${ }^{23}$ Although many of these chronic conditions may be unavoidable given our current state of knowledge, many deaths in those with mental illness appear to be avoidable. $^{24}$ Unfortunately, medical disorders are often overlooked by mental health specialists in psychiatric settings and by physicians in primary care and medical settings. As a result up to half of all chronic conditions may go unrecognised in severe mental illness. ${ }^{25-29}$ In addition, many people with mental ill health who have an unmet need for medical care also have other risk factors for poor treatment such as low income, social isolation, homelessness, substance misuse and lack of healthcare insurance. $^{30}$

Given these numerous concerns regarding quality of medical care, elevated mortality and low receipt of preventive services for people with a psychiatric disorder, we undertook a data synthesis of comparative studies that have examined the adequacy of medication prescribing for existing physical disorders in individuals with and without severe mental illness. To the best of our knowledge this is the first meta-analysis using prescribing data in mental ill health groups.

\section{Method}

\section{Search and appraisal}

A review strategy and extraction sheet was agreed according to the PRISMA standard. We decided to focus on non-organic 
psychiatric disorders, thus excluding studies pertaining to delirium or dementia. ${ }^{31}$ We searched Medline/PubMed and Embase abstract databases from inception to November 2010. The initial search strategy is listed in the online supplement. We included any study (observational/interventional) that had measured the prescription or receipt of medication for medical conditions in patients with and without defined mental illness. Four full-text collections were searched: Science Direct, Ingenta Select, Springer-Verlag's LINK and Blackwell-Wiley. In these online databases the same search terms were used but as a full-text search and as a citation search. The abstract databases Web of Knowledge and Scopus were searched, using the terms in the online supplement as a text-word search, and using key papers in a reverse citation search. Finally, a number of journals were hand-searched (British Journal of Psychiatry, Schizophrenia Research, Schizophrenia Bulletin, Psychological Medicine, Acta Psychiatrica Scandavica, American Journal of Psychiatry, Archives of General Psychiatry, Canadian Journal of Psychiatry, Journal of Psychiatric Research, Psychiatric Services, The Psychiatrist (previously known as Psychiatric Bulletin); all from 2000) and several experts contacted. Using this strategy we identified 84 primary data publications and of these 61 reported aspects of quality of medical care other than prescribed medication. Several were excluded due to lack of extractable data despite attempts to find data from the original authors. ${ }^{32}$ Data were extracted by two authors (O.L. and A.J.M.) and independently checked by a third (D.F.) (see online supplement). Appraisal of individual studies was performed and the Newcastle-Ottawa evaluation scale for observational studies was used. ${ }^{33}$ In addition, we performed a PRISMA evaluation of our meta-analysis using a standard checklist of 27 items that ensure the quality of a systematic review or meta-analysis. ${ }^{34}$ The Newcastle-Ottawa evaluation scale is a specific set of nine items used to evaluate individual studies. All medication listed in each publication was fully extracted to avoid meta-analytic bias resulting in 61 drug-level analyses.

\section{Meta-analysis}

From the available data, we entered or calculated odds ratios (OR) and $r$ values. We extracted data on the rate of prescribed medication is those with $v$. without mental illness. Relative risks (hazard ratios) were converted into odds ratios with reference to the reported control event rate, an adaption of a method described elsewhere. ${ }^{35}$ We then used a summary meta-analysis, pooling odds ratios. We attempted to account for potential confounders but these were variably handled by primary studies. We therefore extracted and stratified results into adjusted and unadjusted analysis and specified types of adjustment. Confidence intervals were obtained from all studies or calculated from the data provided. Between-study heterogeneity was assessed using the $I^{2}$ statistic. ${ }^{36}$ Heterogeneity was reduced by stratifying by either type of mental illness or drug class or type of medical condition. Where heterogeneity (defined by $>80 \% I^{2}$ ) was high, random-effects meta-analysis was preferred otherwise fixed-effects meta-analysis was used. We applied a minimum data-set rule, namely we required a minimum of three independent studies to justify pooling by individual drug class, a convention advised by a number of statistical programs such as STATA. Statsdirect version 2.7.7 for Windows was used to pool studies using the DerSimonian-Laird method for random-effects meta-analysis. Potential study bias was examined using Kendall's tau and Egger bias statistics, ${ }^{37}$ but no evidence of publication bias was detected (see online supplement). In order to offer a qualitative interpretation of quantitative data we defined the following grades of treatment adequacy a priori with reference to the comparator population rates: $<80 \%$ 'inadequate'; $\geqslant 80 \%<90 \%$ 'suboptimal'; $\geqslant 90 \%<95 \%$ 'inequitable'; and $\geqslant 95 \%$ 'adequate'.

\section{Results}

Our search identified 61 drug-level analyses regarding prescribing adequacy in 23 publications ${ }^{38-60}$ involving 1931509 patients (study-level results shown in online Table DS1; overview of search results shown in Fig. 1). Subgroups included 13 analyses (36 druglevel comparisons) in patients with severe mental illness, 8 analyses (13 comparisons) in patients with affective disorder and 7 analyses (12 comparisons) for other miscellaneous mental illness groups. We used British National Formulary (BNF) codes to classify medications (www.bnf.org). In total, there were 12 classes of medication in the analysis: angiotensin-converting enzyme inhibitors or angiotensin II receptor blockers (ACE inhibitors/ ARBs, BNF 2.5.5.1 and 2.5.5.5.2), nitroglycerine (BNF 2.6.1), anti-inflammatory medication for arthritis (BNF 4.7.1), antiplatelet drugs (BNF 2.9), anticoagulants (BNF 2.8), beta-blockers (BNF 2.4), cytotoxic chemotherapy (BNF 8.1), insulin (BNF 6.1.1), highly active antiretroviral therapy (HAART, BNF 5.3.1), lipid-regulating drugs (includes statin and non-statins, BNF 2.12) and medication for osteoporosis (largely hormone replacement therapy (HRT), BNF 6.4.1.1). Thus, most were for cardiovascular health indications. We evaluated the quality of studies using the Newcastle-Ottawa criteria (online Table DS2). Using these nine domains we rated 2 studies as having a low overall quality, 12 as having moderate overall quality and 9 with high overall quality but all were considered sufficient for analysis.

\section{Severe mental illness (including schizophrenia)}

There were 36 analyses of drug prescribing from a combined pool of over 1.5 million individuals (Fig. 2). The pooled odds ratio for equitable prescribing was 0.74 (95\% CI $0.63-0.86)$ favouring non-mental ill health. $I^{2}$ was 97.2 suggesting high heterogeneity. Lower than expected receipt of medication was in evidence for ACE/ARBs $(\mathrm{OR}=0.89,95 \%$ CI $0.81-0.98, P=0.02)$, beta-blockers $(\mathrm{OR}=0.90,95 \% \mathrm{CI} 0.84-0.96, P=0.001)$ and statins $(\mathrm{OR}=0.61$, 95\% CI $0.39-0.94, P=0.02$ ) but not for anticholesterol drugs in general (statins and non-statins combined), or for anticoagulants (aspirin and non-aspirin combined). However, for non-aspirin anticoagulants alone (clopidogrel and ticlopidine) there was a significantly lower rate $(\mathrm{OR}=0.74,95 \%$ CI $0.56-0.97, P=0.02)$. Results were similar when stratified by schizophrenia alone. For schizophrenia alone the pooled odds ratio across all medication was 0.69 (95\% CI $0.57-0.83, P<0.0001)$.

\section{Affective disorder}

Across 13 analyses involving 232882 individuals the $I^{2}$ was $94.6 \%$. The combined meta-analysis showed a trend towards low receipt with a pooled odds ratio of 0.75 (95\% CI $0.55-1.02, P=0.07)$, which was significant in fixed-effect but not random-effects analysis (Fig. 3). Lower receipt of medication was evident for beta-blockers ( $\mathrm{OR}=0.76,95 \% \mathrm{CI} 0.45-1.29)$ and lipid-regulating drugs ( $\mathrm{OR}=0.92,95 \% \mathrm{CI} 0.64-1.32$ ), but neither were statistically significant. There was inadequate data to examine other classes of medication.

\section{Other mental illness}

Across 12 analyses (involving 19637 individuals with mental illness from a sample of 188627 ) the $I^{2}$ was $64.5 \%$, suggesting low heterogeneity and permitting fixed-effects analysis. The 


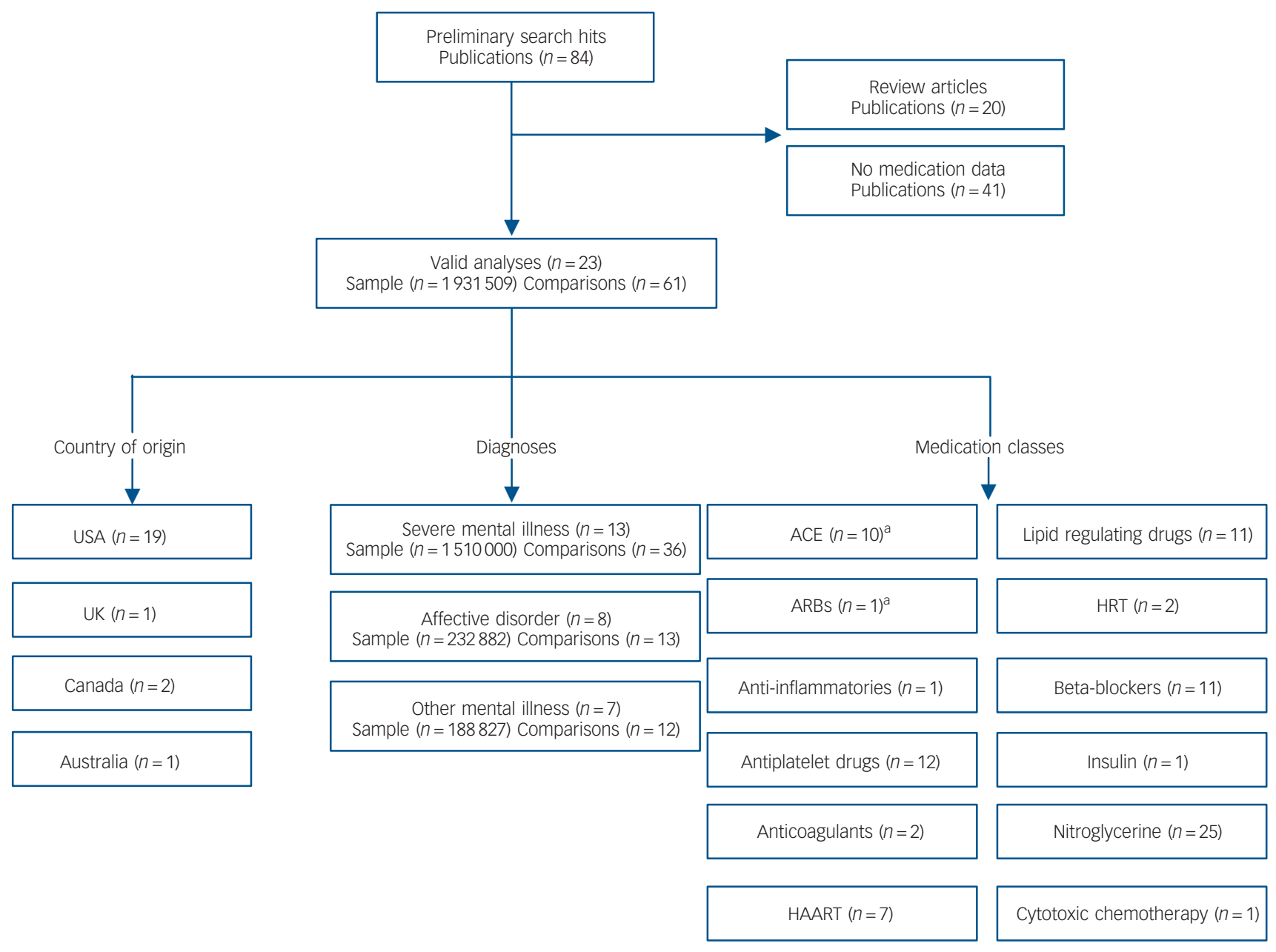

Fig. 1 Quorom overview of search results.

ACE, angiotensin-converting enzyme inhibitor; ARB, angiotensin receptor blocker; HRT, hormone replacement therapy; HAART, highly active antiretroviral therapy. a. Classes usually combined by convention.

combined pooled odds ratio was 0.95 (95\% CI 0.92-0.98, Fig. 4). Lower receipt of medication was evident for ACE or ARBs $(\mathrm{OR}=0.92,95 \%$ CI $0.85-0.99)$ but not HAART medication $(\mathrm{OR}=0.98,95 \%$ CI $0.75-1.28)$. There was inadequate data to examine other classes of medication.

A summary of results is shown in Table 1.

\section{Discussion}

\section{Main findings}

We found 61 comparative analyses relating to the prescription of 12 classes of medication including lipid-regulating agents (includes statins), beta-blockers, antiplatelet and anticoagulant drugs, ACE/ARBs, insulin, cytotoxic chemotherapy, antiinflammatories, HRT for osteoporosis and HAART for HIV. Patients with severe mental illness had an odds ratio of 0.74 (95\% CI 0.63-0.86) for a comparable medication prescription. The differences were found largely in drugs for cardiovascular indications. For example, patients with severe mental illness received lower than expected prescriptions for ACE/ARBs, betablockers and statins. Combining all types of mental illness and all classes of drug suggested that patients with any type of mental illness had an odds ratio of 0.78 (95\% CI $0.73-0.84, P=0.0001)$ of comparable medication (data not shown). Given a typical control event rate (i.e. receipt of medication in the comparison group) of
$70 \%$, the actual rate of undertreatment can be estimated at $8 \%$ (95\% CI 5-12) in those with other mental illness, $10 \%$ in those with severe mental illness and $12 \%$ in schizophrenia, a disparity that could be classified as 'inequitable' or 'suboptimal' receipt of medication according to our a priori definition.

\section{Limitations}

Several limitations should be acknowledged. First, we had no a priori protocol for this study but attempted to follow the review strategy suggested in the PRISMA standard. Heterogeneity was found in 5 out of 11 main analyses (Table 1) and this had the effect of rendering the odds ratios observed for affective disorders non-significant. We used the Newcastle-Ottawa scale, which is only one of several possible methods. ${ }^{61}$ In two studies involving HAART there was no adjustment made for demographic, illness or prescribing variables ${ }^{51,60}$ (see Table DS1) and therefore these data should be interpreted with caution. Without adjustment it is possible that the group with mental illness had more severe physical illness than the comparison group - although this should of course favour higher rates of prescribing, not lower rates. One study reported hazard ratios with no control event rate, ${ }^{46}$ therefore we estimated the control event rate using data from related publications from the same group (pending confirmation from the authors). Another limitation is that the definition of mental illness, particularly severe mental illness varied 
ACE: Blecker et al ${ }^{40}$

ACE: Kisely et a/ ${ }^{49}$

ACE: Kreyenbuhl et a/ ${ }^{50}$

ACE: Petersen et a $\left.\right|^{52}$

ACE: Suvisaari et a/ ${ }^{56}$

ACE-I or ARB: Weiss et al ${ }^{59}$

Anticoagulant - clopidogrel (IHD): Kisely et a ${ }^{49}$ Anticoagulant - clopidogrel (stroke): Kisely et al ${ }^{49}$ Anticoagulant - ticlopidine: Kisely et a ${ }^{49}$ Arthritis: Baxter et al ${ }^{38}$ Arthritis: Redelmeier et a/ ${ }^{55}$ Aspirin: Desai et $a l^{43}$ Aspirin: Hippisley-Cox et a/48 Aspirin: Petersen et al/ ${ }^{52}$ Aspirin: Weiss et a ${ }^{59}$ Aspirin/anticoagulant: Suvisaari et a $1^{56}$ Beta-blocker: Blecker et al ${ }^{40}$

Beta-blocker: Desai et al ${ }^{43}$ Beta-blocker: Hippisley-Cox et al ${ }^{48}$ Beta-blocker: Kisely et a/ ${ }^{49}$ Beta-blocker: Weiss et al ${ }^{59}$ Beta-blockers: Petersen et a/ ${ }^{52}$ Beta-blockers: Suvisaari et al ${ }^{56}$

Cholesterol: Desai et al ${ }^{43}$

Cholesterol: Kisely et al ${ }^{49}$ Cholesterol: Redelmeier et al ${ }^{55}$ Cholesterol: Weiss et al ${ }^{59}$ HAART: Himelhoch et al ${ }^{46}$ Insulin: Weiss et al ${ }^{59}$ Nitroglycerine: Suvisaari et a ${ }^{56}$ Osteoporosis: Bishop et a/ ${ }^{39}$ Osteoporosis/HRT: Redelmeier et al ${ }^{55}$ Statin: Hippisley-Cox et al ${ }^{48}$ Statin: Kreyenbuhl et a/50

Statin: Weiss et al ${ }^{59}$ Warfarin: Kisely et al ${ }^{49}$ combined

$$
0.1
$$

$1.09(0.84-1.45)$

$0.89(0.76-1.04)$

$0.23(0.12-0.44)$

$0.92(0.79-1.09)$

$1.10(0.30-3.70)$

$0.83(0.61-1.14)$

$1.10(0.30-3.70)$

$0.83(0.61-1.14)$

$0.62(0.42-0.90)$

$0.80(0.44-1.48)$

$0.96(0.57-1.63)$

$0.77(0.66-0.90)$

$0.59(0.57-0.62)$

$0.96(0.81-1.15)$

$0.89(0.64-1.24)$

$0.85(0.33-2.10)$

$1.27(0.98-1.71)$

$0.70(0.43-1.15)$

$0.96(0.88-1.06)$

$0.82(0.71-0.95)$

$0.96(0.54-1.71)$

$0.78(0.69-0.92)$

$0.41(0.15-1.10)$

$1.01(0.37-2.77)$

$0.51(0.41-0.63)$

$0.22(0.20-0.25)$

$1.85(1.11-3.09)$

$0.85(0.71-1.23)$

$1.44(0.96-2.16)$

$1.10(0.39-2.60)$

$0.38(0.15-0.97)$

$0.29(0.26-0.33)$

$0.85(0.80-0.91)$

$0.29(0.11-0.77)$

$0.54(0.36-0.51)$

$0.55(0.36-0.85)$

$0.74(0.63-0.86)$

\section{Fig. 2 Prescribing differences for severe mental illness v. no mental illness: summary meta-analysis plot (random effects).}

ACE, angiotensin-converting enzyme inhibitor; ARB, angiotensin receptor blocker; HAART, highly active antiretroviral therapy; HRT, hormone replacement therapy; IHD, ischaemic heart disease.

considerably between studies, with seven studies defining mental illness using routine clinical interviews and one using prescription of haloperidol as a marker of mental ill health. The remaining studies used ICD-9 coding. A further important limitation is that most studies specified only that the mental health diagnosis was present in the year preceding the prescription of medication and therefore concurrent mental illness, symptoms of mental illness and severity of mental illness cannot be adequately reported. We also note that although the majority of disparities were manifest in drugs prescribed for cardiovascular conditions, the sample size was modest for most other medical conditions. We also note that in all but 1 of the 23 studies the setting was a country where health insurance is operating (largely USA), as opposed to socialised healthcare. Further studies should examine potential prescribing inequalities in countries with nationalised healthcare. Finally, and perhaps most importantly, all but two studies (see overleaf) measured prescribing from electronic databases based on naturalistic observational data and thus no information was available on patient $v$. prescriber influences on low receipt of necessary medication. 
Arthritis: Baxter et $a^{\beta 8}$

ACE: Kreyenbuhl et a ${ }^{50}$

Aspirin: Desai et a/43

Beta-blocker: Desai et al ${ }^{43}$ Beta-blocker: Hippisley-Cox et a/48

Beta-blocker: Wang et al ${ }^{58}$

Chemotherapy: Goodwin et al/5

Cholesterol: Desai et a/43

Cholesterol: Hippisley-Cox et a/ ${ }^{48}$

HAART: Tegger et $a^{17}$

HAART: Yun et alo0

Statin: Hippisley-Cox et $a^{48}$

Statin: Kreyenbuhl et a ${ }^{50}$

Combined

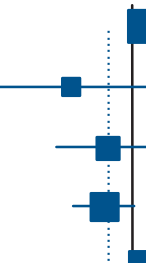

$1.16(1.07-1.26)$

$0.46(0.18-1.19)$

$0.75(0.39-1.43)$

$0.70(0.48-1.03)$

$1.18(0.94-1.56)$

$0.55(0.45-0.55)$

$0.65(0.43-1.00)$

$1.31(0.57-3.00)$

$0.86(0.70-12.30)$

$0.36(0.30-0.50)$

$1.43(1.18-1.74)$

$1.15(0.80-1.95)$

$0.14(0.05-0.44)$

$0.75(0.55-1.02)$

$\begin{array}{lllllllll}0.01 & 0.1 & 0.2 & 0.5 & 1 & 2 & 5 & 10 & 100 \\ \text { Odds ratio }(95 \% \mathrm{Cl}) & & \end{array}$

Fig. 3 Prescribing differences for affective disorder $v$. no mental illness: summary meta-analysis plot (random effects).

ACE, angiotensin-converting enzyme inhibitor; HAART, highly active antiretroviral therapy.

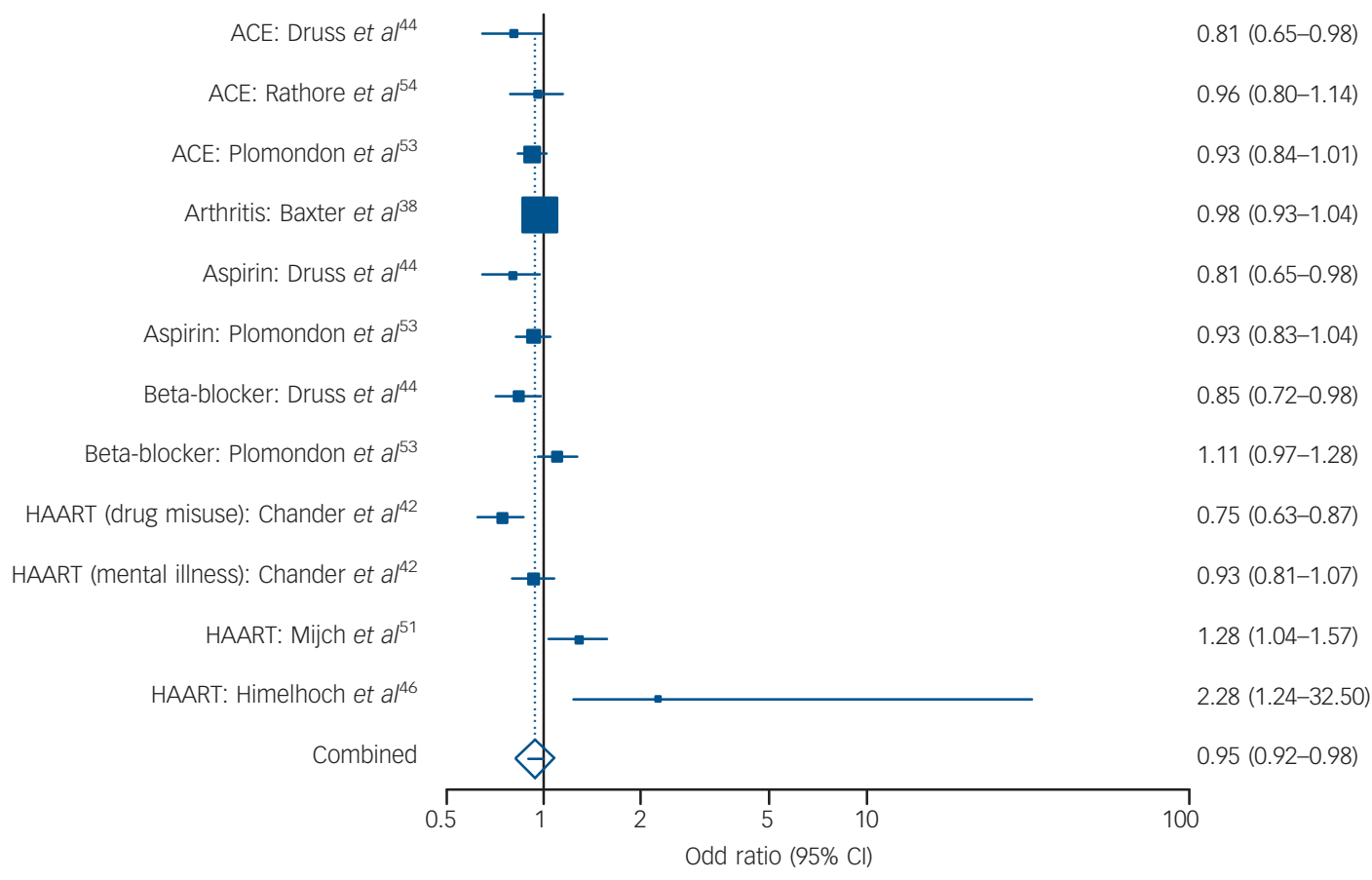

Fig. 4 Prescribing differences for other mental illness ${ }^{a}$ v. no mental illness: summary meta-analysis plot (fixed effects).

ACE, angiotensin-converting enzyme inhibitor; HAART, highly active antiretroviral therapy.

a. Other mental illness includes any type of mental ill health other than pure affective disorder, severe mental illness or schizophrenia.

\section{Possible explanations for suboptimal prescribing}

It is already widely known that people with mental ill health have problems with psychotropic medication adherence. ${ }^{62,63}$ This also applies to adherence to physical health medications. ${ }^{64-66}$ However, the studies reviewed here measure medication prescribing according to notations in medication databases (with the exception of Bishop et al who used notations in medical notes $^{39}$ and Suvisaari et al who used patient-reported medication at interview $\left.{ }^{56}\right)$. Thus, uptake of medication and adherence to medication was not measured. We suggest therefore that the amount of medication actually taken as directed was probably less than that recorded here, and actual disparities in medication consumption may be more severe than disparities in prescribing. 


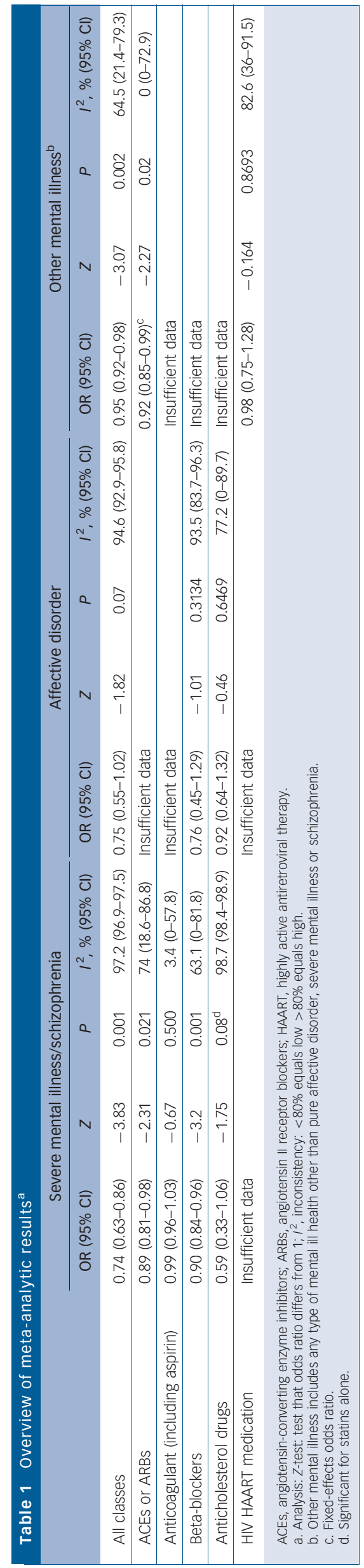

That said, some studies have found no difference or higher medication adherence to psychotropic drugs compared with physical health medication. ${ }^{67,68}$ It may be important to acknowledge that insurance coverage influences uptake of medication in the USA and Canada. ${ }^{69}$ However, the studies here do not measure uptake but rather prescribing. As many people with mental illness are unaware of their formal medical diagnosis and uninformed about their physical health medication, ${ }^{56}$ we suggest that the disparities noted are more likely to relate to physician habits than patient preferences.

Where physical health medication is prescribed by mental health professionals several factors may influence underprescribing. Previous work has shown that mental health professionals often miss physical conditions in their patients $\mathrm{s}^{26,70,71}$ and undertake physical examinations in less than $50 \%$ of their patients. ${ }^{72}$ Mental health professionals often do not feel confident in prescribing physical health medication. Yet in the majority of cases physical health medication is prescribed by physicians in primary care, internal medicine and related medical specialties. We already know that mental health status and prescription of antipsychotics reduces likelihood of medical monitoring (such as glycated haemoglobin (HBAlc) testing). ${ }^{6,73}$ Primary care physicians often consider such patients to be 'difficult to manage', although many primary care physicians are willing to help with physical healthcare. ${ }^{74,75}$ Where primary care physicians lack expertise in mental health they are less likely to offer general care to those with mental illness. ${ }^{76}$ Similarly when people with mental illness attend emergency departments they are less likely to be offered hospital care than other people. ${ }^{77}$ In general practice, cardiovascular risk factors are often recorded in the medical records for adults with long-term mental illness, but primary care physicians appear reluctant to intervene. ${ }^{78}$ Clinician factors such as willingness to investigate, ability and enthusiasm to treat and willingness to offer follow-up are important predictors of quality of care. Because of medical and psychiatric comorbidity, seemingly unrelated conditions compete for clinicians' attention. ${ }^{79}$ Against this, studies suggest that the adequacy of medical care may not be adversely influenced by the number of comorbid medical disorders. ${ }^{80,81}$ Indeed, some have found that comorbidity favours superior care by virtue of higher than average healthcare visits. ${ }^{82}$ Indirect evidence suggests that clinicians' attitudes towards patients directly influence health outcomes. In one study in primary care, poor mental health status was linked with poor accessibility, poorer general practitioner attitude and less time spent with the general practitioner. ${ }^{83}$ In a study of 59 patients seen in a US community mental health centre, $14 \%$ reported that they used the medical emergency department for their routine medical care needs and $45 \%$ said that their mental health provider did not ask them about medical issues. ${ }^{84}$

Three mitigating factors might explain low physician prescribing of physical health medication namely cautious prescribing, deferred prescribing and low patient acceptance of suggested medication. Regarding intentionally cautious prescribing, physicians' prescription of cardiovascular medication may be cautious in light of possible links with suicide. ${ }^{85}$ Most plausibly this could apply to cholesterol-lowering agents, ${ }^{86,87}$ betablockers ${ }^{88}$ and angiotensin-receptor antagonists. ${ }^{89}$ Less likely but theoretically possible, physicians might be cautious about using aspirin together with selective serotonin reuptake inhibitors due to gastrointestinal bleeding, and ACE inhibitors and beta-blockers in people with mental illness who smoke. A second possibility is that treatment in some circumstances is deferred rather than omitted, although evidence suggests that in the context of mental illness most deferred treatment is not received at a later date. ${ }^{90} \mathrm{~A}$ third hypothesis underlying inadequate prescriptions is low uptake of care on account of patient preference. It is not yet clear 
if this is the primary explanation. ${ }^{91-93}$ For example, Salsberry and colleagues (2005) found that compared with the general population, those with severe mental illness had more emergency department visits and visited a doctor more frequently, but despite this high healthcare utilisation had very low rates of cervical smears and mammograms. ${ }^{94}$ People with mental ill health perceive barriers to accessing primary physical healthcare. ${ }^{84,92,95-97}$ Patients often cite lack of availability of medical advice and poor quality of medical advice as influential. ${ }^{84,98,99}$ Observational evidence shows many have difficulty getting timely access to appropriate primary healthcare. ${ }^{27,97,100,101}$ For example, data from the 1999 Large Health Survey of Veterans found that veterans with schizophrenia, bipolar disorder or a drug use disorder were less likely to have had any primary care visit than those without these diagnoses, even after controlling for medical comorbidity. ${ }^{101}$

\section{Intervention to improve therapeutic care}

Assuming these disparities in prescribing are robust, what can be done to improve quality of medical care? Druss \& von Esenwein $(2006)^{102}$ reviewed six randomised trials designed to improve medical care in psychiatric conditions. These studies demonstrated a substantial positive impact on linkage to and quality of medical care albeit with a diverse range of interventions. One study showed that a simple intervention could improve readiness to begin HAART. ${ }^{103}$ Ismail et al and Winkley et al pooled 46 trials regarding the effect of psychological treatment on glycaemic control but showed only very modest effects in adults. ${ }^{104,105}$ Anderson et al (1998) reported a meta-analysis of 43 studies involving strategies to improve the delivery of preventive care that could hold valuable lessons. ${ }^{106}$ In general, interventions were moderately effective in improving immunisation, screening and counselling. ${ }^{106}$ In this data-set, two studies examined the effect of antidepressant treatment on HAART utilisation in patients with depression. Tegger et al (2008) found that untreated patients were $40 \%$ as likely to receive HAART; in treated patients there was no significant difference. ${ }^{57}$ Similarly, Cook et al found that mental health treatment increased the probability of self-reported HAART use. ${ }^{32}$ Primary care physician recommendation of screening has been shown to be one of the strongest predictors of receipts of screening. ${ }^{107-110}$ Better communication between primary care providers and specialist mental health services might improve prescribing for mental and physical ill health. ${ }^{75,111}$ However, in a trial of an integrated model of care for older people, the intervention helped with access but did not produce any significant treatment effects for depression or anxiety. ${ }^{112}$

From a research perspective, a detailed examination of patient and provider influences on received medication is urgently needed. Clinically, we suggest that treatment of comorbid physical conditions is prioritised in patients with mental health concerns and closely monitored. ${ }^{113}$ Clinicians caring for patients with physical and mental illness should take particular care to ensure optimal treatment is maintained in both areas. At an organisation level, monitoring systems are needed to ensure that the medical care of people with mental ill health is not overlooked.

\footnotetext{
Alex J. Mitchell, MRCPsych, Department of Psycho-oncology, Leicestershire
Partnership Trust and Department of Cancer Studies and Molecular Medicine, Partnership Trust and Department of Cancer Studies and Molecular Medicine,
University of Leicester, Leicester, UK; Oliver Lord, MRCPsych, Crisis Resolution and Home Treatment Team, Leicestershire Partnership Trust, Leicester, UK; Darren Malone, MRCPsych, Older People Mental Health Services, Lakes District Health Board, New Zealand

Correspondence: Alex J. Mitchell, MRCPsych, Department of Psycho-oncology Leicestershire Partnership Trust, Leicester LE5 OTD, UK. Email: ajm80@le.ac.uk

First received 24 Mar 2011, final revision 6 Feb 2012, accepted 3 Apr 2012
}

\section{Acknowledgements}

We thank David Ferguson for helping with the extraction of quality appraisal of primary studies

\section{References}

1 Unützer J, Schoenbaum, M, Druss BG, Katon WJ. Transforming mental health care at the interface with general medicine: report for the Presidents Commission. Psychiatr Serv 2006; 57: 37-47.

2 De Hert M, Dekker JM, Wood D, Kahl KG, Holt RI, Möller HJ. Cardiovascular disease and diabetes in people with severe mental illness position statement from the European Psychiatric Association (EPA), supported by the European Association for the Study of Diabetes (EASD) and the European Society of Cardiology (ESC). Eur Psychiatry 2009; 24: 412-24.

3 National Institute for Health and Clinical Excellence. Schizophrenia: Core Interventions in the Treatment and Management of Schizophrenia in Adults in Primary and Secondary Care (Update). NICE, 2011 (http://www.nice.org.uk/CG82).

4 Fleischhacker WW, Cetkovich-Bakmas M, De Hert M, Hennekens $\mathrm{CH}$, Lambert M, Leucht $S$, et al. Comorbid somatic illnesses in patients with severe mental disorders: clinical, policy, and research challenges. J Clin Psychiatry 2008; 69: 514-9.

5 Ruiz JS, Garcia JB, Ruiloba JV, Giner Ubago J, García-Portilla González MP. Consensus on physical health of patients with schizophrenia from the Spanish Societies of Psychiatry and Biological Psychiatry [in Spanish]. Actas Esp De Psiquiatr 2008; 36: 251-64.

6 Mitchell AJ, Malone D, Carney Doebbeling C. Quality of medical care for people with and without comorbid mental illness and substance misuse: systematic review of comparative studies. Br J Psychiatry 2009; 194: 491-9.

7 Roberts L, Roalfe A, Wilson S, Lester N. Physical health care of patients with schizophrenia in primary care: a comparative study. Fam Pract 2007; 24: $34-40$.

8 Vahia IV, Diwan S, Bankole AO, Kehn M, Nurhussein M, Ramirez P, et al. Adequacy of medical treatment among older persons with schizophrenia. Psychiatr Serv 2008; 59: 853-9.

9 Desai MM, Rosenheck RA, Druss BG, Perlin JB. Mental disorders and quality of diabetes care in the veterans health administration. Am J Psychiatry 2002; 159: $1584-90$

10 Mateen FJ, Jatoi A, Lineberry TW, Aranguren D, Creagan ET, Croghan GA, et al. Do patients with schizophrenia receive state-of-the-art lung cancer therapy? A brief report. Psychooncology 2008; 17: 721-5.

11 Li Y, Glance LG, Cai X, Mukamel DB. Adverse hospital events for mentally-ill patients undergoing coronary artery bypass surgery. Health Serv Res 2008; 43: 2239-52.

12 Copeland LA, Zeber JE, Pugh MJ, Mortensen EM, Restrepo MI, Lawrence VA. Postoperative complications in the seriously mentally ill - a systematic review of the literature. Ann Surgery 2008; 248: 31-8.

13 Saha S, Chant D, McGrath J. A systematic review of mortality in schizophrenia - is the differential mortality gap worsening over time? Arch Gen Psychiatry 2007; 64: 1123-31.

14 Prince M, Patel V, Saxena S, Maj M, Maselko J, Phillips MR, et al. No health without mental health. Lancet 2007; 370: 859-77.

15 Mitchell AJ, Malone D. Physical health and schizophrenia. Curr Opin Psychiatry 2006; 19: 432-7.

16 Carney $\mathrm{CP}$, Jones L, Woolson RF. Medical comorbidity in women and men with schizophrenia: a population-based controlled study. J Gen Intern Med 2006; 21: 1133-7.

17 Weber NS, Cowan DN, Millikan AM, Niebuhr DW. Psychiatric and general medical conditions comorbid with schizophrenia in the national hospital discharge survey. Psychiatr Serv 2009; 60: 1059-67.

18 Perron BE, Howard MO, Nienhuis JK, Bauer MS, Woodward AT, Kilbourne AM. Prevalence and burden of general medical conditions among adults with bipolar I disorder: results from the National Epidemiologic Survey on Alcohol and Related Conditions. J Clin Psychiatry 2009; 79: 1407-15.

19 Kisely S, Simon G. An international study of the effect of physical ill health on psychiatric recovery in primary care. Psychosom Med 2005; 67: 116-22.

20 Zolnierek CD. Non-psychiatric hospitalization of people with mental illness: systematic review. J Adv Nurs 2009; 65: 1570-83.

21 Chwastiak L, Rosenheck R, Leslie D. Impact of medical comorbidity on the quality of schizophrenia pharmacotherapy in a national VA sample. Med Care 2006; 44: 55-61. 
22 Mackell JA, Harrison DJ, McDonnell DD. Relationship between preventative physical health care and mental health in individuals with schizophrenia: a survey of caregivers. Ment Health Serv Res 2005; 7: 225-8.

23 Lord O, Mitchell AJ, Malone D. Receipt of preventive medical care and medical screening for patients with mental illness: a comparative analysis. Gen Hosp Psychiatry 2010; 32: 519-43.

24 Amaddeo F, Barbui C, Perini G, Biggeri A, Tansella M. Avoidable mortality of psychiatric patients in an area with a community-based system of mental health care. Acta Psychiatr Scand 2007; 115: 320-5.

25 Kilbourne AM, McCarthy JF, Welsh D, Blow F. Recognition of co-occurring medical conditions among patients with serious mental illness. J Nerv Ment Dis 2006; 194: 598-602.

26 Koranyi E. Morbidity and rate of undiagnosed physical illness in a psychiatric population. Arch Gen Psychiatry 1979; 36: 414-9.

27 Farmer S. Medical problems of chronic patients in a community support program. Psychiatr Serv 1987; 38: 745-9.

28 Fallow S, Bowler C, Dennis M, Jones P. Undetected physical illness in older referrals to a community mental-health-service. Int J Geriatr Psychiatry 1995 10: 74-5.

29 Bernardo M, Banegas JR, Canas F, Casademot X, Riesgo Y, Varela C. Low level of medical recognition and treatment of cardiovascular risk factors in patients with schizophrenia in Spain. 13th Biennial Winter Workshop on Schizophrenia Research. Schizophr Res 2006; 81 (suppl): 176-7.

30 Desai MM, Rosenheck RA. Unmet need for medical care among homeless adults with serious mental illness. Gen Hosp Psychiatry 2005; 27: 418-25.

31 Muther J, Abholz HH, Wiese B, Fuchs A, Wollny A, Pentzek M. Are patients with dementia treated as well as patients without dementia for hypertension, diabetes, and hyperlipidaemia? Br J Gen Pract 2010; 60: 671-4.

32 Cook JA, Grey D, Burke-Miller J, Cohen MH, Anastos K. Effects of treated and untreated depressive symptoms on highly active antiretroviral therapy use in a US multi-site cohort of HIV-positive women. AIDS Care 2006; 18: 93-100.

33 Wells GA, Shea B, O'Connell D, Peterson J, Welch V, Losos M, Tugwell P. The Newcastle-Ottawa Scale (NOS) for Assessing the Quality of Nonrandomised Studies in Meta-analyses. Ottawa Hospital Research Institute, 2011 (http:// www.ohri.ca/programs/clinical_epidemiology/oxford.asp).

34 Moher D, Liberati A, Tetzlaff J, Altman DG. Preferred reporting items for systematic reviews and meta-analyses: the PRISMA statement. BMJ 2009; 339: b2535

35 Zhang JM, Yu KF. What's the relative risk? A method of correcting the odds ratio in cohort studies of common outcomes. JAMA 1998; 280: 1690-1.

36 Higgins JPT, Thompson SG, Deeks JJ, Altman DG. Measuring inconsistency in meta-analyses. BMJ 2003; 327: 557-60.

37 Peters JL, Sutton AJ, Jones DR, Abrams KR, Rushton L. Comparison of two methods to detect publication bias in meta-analysis. JAMA 2006; 295 676-80

38 Baxter JD, Samnaliev M, Clark RE. The quality of asthma care among adults with substance-related disorders and adults with mental illness. Psychiatr Serv 2009; 60: 43-9.

39 Bishop JR, Alexander B, Lund BC, Klepser TB. Osteoporosis screening and treatment in women with schizophrenia: a controlled study. Pharmacotherapy 2004; 24: 515-21.

40 Blecker S, Zhang Y, Ford DE, Guallar E, Dosreis S, Steinwachs DM, et al. Quality of care for heart failure among disabled Medicaid recipients with and without severe mental illness. Gen Hosp Psychiatry 2010; 32: 255-61.

41 Bogart LM, Fremont AM, Young AS, Pantoja P, Chinman M, Morton S, et al. Patterns of HIV care for patients with serious mental illness. AIDS Patient Care STDS 2006; 20: 175-82.

42 Chander G, Himelhoch S, Fleishman JA, Hellinger J, Gaist P, Moore RD, et al. HAART receipt and viral suppression among HIV-infected patients with cooccurring mental illness and illicit drug use. AIDS Care 2009; 21: 655-63.

43 Desai MM, Rosenheck RA, Druss BG, Perlin JB. Mental disorders and quality of care among postacute myocardial infarction outpatients. J Nerv Ment Dis 2002; 190: 51-3.

44 Druss BG, Bradford WD, Rosenheck RA, Radford MJ, Krumholz HM. Quality of medical care and excess mortality in older patients with mental disorders. Arch Gen Psychiatry 2001; 58: 565-72.

45 Goodwin JS, Zhang DD, Ostir GV. Effect of depression on diagnosis, treatment, and survival of older women with breast cancer. J Am Geriatr Soc 2004; 52: 106-11.

46 Himelhoch S, Moore RD, Treisman G, Gebo KA. Does the presence of a current psychiatric disorder in AIDS patients affect the initiation of antiretroviral treatment and duration of therapy? J Acquir Immune Defic Syndr 2004; 37: 1457-63.

47 Himelhoch S, Chander G, Fleishman JA, Hellinger J, Gaist P, Gebo KA, et al. Access to HAART and utilization of inpatient medical hospital services among
HIV-infected patients with co-occurring serious mental illness and injection drug use. Gen Hosp Psychiatry 2007; 29: 518-25.

48 Hippisley-Cox J, Parker C, Coupland C, Vinogradova Y. Inequalities in the primary care of patients with coronary heart disease and serious mental health problems: a cross-sectional study. Heart 2007; 93: 1256-62.

49 Kisely S, Campbell LA, Wang Y. Treatment of ischaemic heart disease and stroke in individuals with psychosis under universal healthcare. $\mathrm{Br} \mathrm{J}$ Psychiatry 2009; 195: 545-50.

50 Kreyenbuhl J, Dickerson F, Medoff D, Brown CH, Goldberg RW, Fang L, et al. Extent and management of cardiovascular risk factors in patients with type 2 diabetes and serious mental illness. J Nerv Ment Dis 2006; 194: 404-10.

51 Mijch A, Burgess P, Judd F, Grech P, Komiti A, Hoy J, et al. Increased health care utilization and increased antiretroviral use in HIV-infected individuals with mental health disorders. HIV Med 2006; 7: 205-12.

52 Petersen LA, Normand SL, Druss BG, Rosenheck RA. Process of care and outcome after acute myocardial infarction for patients with mental illness in the VA health care system: are there disparities? Health Serv Res 2003; 38: 41-63.

53 Plomondon ME, Michael Ho PM, Wang L, Greiner GT, Shore JH, Sakai JT, et al. Severe mental illness and mortality of hospitalized ACS patients in the VHA. BMC Health Serv Res 2007; 7: 146.

54 Rathore SS, Wang Y, Druss BG, Masoudi FA, Krumholz HM. Mental disorders, quality of care, and outcomes among older patients hospitalized with heart failure: an analysis of the national heart failure project. Arch Gen Psychiatry 2008; 65: 1402-8.

55 Redelmeier D, Tan SH, Booth GL. The treatment of unrelated disorders in patients with chronic medical diseases. N Eng J Med 1998; 338: 1516-20.

56 Suvisaari J, Jonna Perälä J, Saarni SI, Kattainen A, Lönnqvist J, Reunanen A. Coronary heart disease and cardiac conduction abnormalities in persons with psychotic disorders in a general population. Psychiatry Res 2010; 175 126-32.

57 Tegger MK, Crane HM, Tapia KA, Uldall KK, Holte SE, Kitahata MM. The effect of mental illness, substance use, and treatment for depression on the initiation of highly active antiretroviral therapy among HIV-infected individuals. AIDS Patient Care STDS 2008; 22: 233-43.

58 Wang PS, Avorn J, Brookhart MA, Mogun H, Schneeweiss S, Fischer MA, et al. Effects of noncadiovascular comorbidities on antihypertensive use in elderly hypertensives. Hypertension 2005; 46: 273-9.

59 Weiss AP, Henderson DC, Weilburg JB, Goff DC, Meigs JB, Cagliero E, et al. Treatment of cardiac risk factors among patients with schizophrenia and diabetes. Psychiatr Serv 2006; 57: 1145-52.

60 Yun LW, Maravi M, Kobayashi JS, Barton PL, Davidson AJ. Antidepressant treatment improves adherence to antiretroviral therapy among depressed HIV-infected patients. J Acquir Immune Defic Syndr 2005; 38: 432-8.

61 Stang A. Critical evaluation of the Newcastle-Ottawa scale for the assessment of the quality of nonrandomized studies in meta-analyses. Eur J Epidemiol 2010; 25: 603-5.

62 Mitchell AJ. High medication discontinuation rates in psychiatry: how often is it understandable? J Clin Psychopharmacol 2006; 26: 109-12.

63 Mitchell AJ, Selmes T. Why don't patients take their medicine? Reasons and solutions in psychiatry. Adv Psychiatr Treat 2007; 13: 336-46.

64 DiMatteo MR, Lepper HS, Croghan TW. Depression is a risk factor for noncompliance with medical treatment: meta-analysis of the effects of anxiety and depression on patient adherence. Arch Intern Med 2000; 160 2101-7.

65 Gonzalez JS, Peyrot M, McCarl LA, Collins EM, Serpa L, Mimiaga MJ, et al. Depression and diabetes treatment nonadherence: a meta-analysis. Diabetes Care 2008; 31: 2398-403.

66 Katon W, Russo J, Lin EH, Heckbert SR, Karter AJ, Williams LH, et al. Diabetes and poor disease control: is comorbid depression associated with poor medication adherence or lack of treatment intensification? Psychosom Med 2009; 71: 965-72

67 Piette JD, Heisler M, Ganoczy D, McCarthy JF, Valenstein M. Differential medication adherence among patients with schizophrenia and comorbid diabetes and hypertension. Psychiatr Serv 2007; 58: 207-12.

68 Himelhoch S, Brown $\mathrm{CH}$, Walkup J, Chander G, Korthius PT, Afful J, et al. HIV patients with psychiatric disorders are less likely to discontinue HAART. AIDS 2009; 23: 1735-42.

69 Mulvale G, Hurley J. Insurance coverage and the treatment of mental illness: effect on medication and provider use. J Ment Health Policy Econ 2008; 11: 177-99.

70 Felker B, Yazell JJ, Short D. Mortality and medical comorbidity among psychiatric patients: a review. Psychiatr Serv 1996; 47: 1356-63. 
71 Koran LM, Sox HC, Marton KI, Moltzen S, Sox CH, Kraemer HC, et al. Medical evaluation of psychiatric patients. 1. Results in a state mental health system. Arch Gen Psychiatry 1989; 46: 733-40.

72 Bobes J, Alegría AA, Saiz-Gonzalez MD, Barber I, Pérez JL, Saiz-Ruiz J. Change in psychiatrists' attitudes towards the physical health care of patients with schizophrenia coinciding with the dissemination of the consensus on physical health in patients with schizophrenia. Eur Psychiatry 2011; 26 305-11.

73 Banta JE, Morrato EH, Lee SW, Haviland MG. Retrospective analysis of diabetes care in California Medicaid patients with mental illness. J Gen Intern Med 2009; 24: 802-8.

74 Lester H, Tritter JQ, Sorohan H. Patients' and health professionals' views on primary care for people with serious mental illness: focus group study. BMJ 2005; 330: 1122.

75 Oud MJT, Schuling J, Slooff CJ, Groenier KH, Dekker JH, Meyboom-de Jong B. Care for patients with severe mental illness: the general practitioner's role perspective. BMC Fam Pract 2009; 10: 29.

76 Fleury MJ, Bamvita JM, Tremblay J. Variables associated with general practitioners taking on serious mental disorder patients. BMC Fam Pract 2009; 10: 41.

77 Sullivan G, Han X, Moore S, Kotrla K. Disparities in hospitalization for diabetes among persons with and without co-occurring mental disorders. Psychiatr Serv 2006; 57: 1126-31.

78 Kendrick T. Cardiovascular and respiratory risk factors and symptoms among general practice patients with long-term mental illness. Br J Psychiatry 1996; 169: 733-9.

79 Piette JD, Kerr EA. The impact of comorbid chronic conditions on diabetes care. Diabetes Care 2006; 29: 725-31.

80 Min LC, Wenger NS, Fung C, Chang JT, Ganz DA, Higashi T, et al. Multimorbidity is associated with better quality of care among vulnerable elders. Med Care 2007; 45: 480-8.

81 Higashi T, Wenger NS, Adams JL, Fung C, Roland M, McGlynn EA, et al. Relationship between number of medical conditions and quality of care. N Engl J Med 2007; 356: 2496-504.

82 Kurdyak PA, Gnam WH. Medication management of depression - the impact of comorbid chronic medical conditions. J Psychosom Res 2004; 57: 565-71.

83 Al-Mandhari AS, Hassan AA, Haran D. Association between perceived health status and satisfaction with quality of care: evidence from users of primary health care in Oman. Fam Pract 2004; 21: 519-27.

84 Levinson Miller C, Druss BG, Dombrowski EA, Rosenheck RA. Barriers to primary medical care among patients at a community mental health center. Psychiatr Serv 2003; 54: 1158-60.

85 Reith DM, Edmonds L. Assessing the role of drugs in suicidal ideation and suicidality. CNS Drugs 2007; 21: 463-72.

86 Muldoon MF, Manuck SB, Mendelsohn AB, Kaplan JR, Belle SH. Cholesterol reduction and non-illness mortality: meta-analysis of randomised clinical trials. BMJ 2001; 322: 11-5.

87 Lester D. Serum cholesterol levels and suicide: a meta-analysis. Suicide Life Threat Behav 2002; 32: 333-46.

88 Sorensen HT, Mellemkjaer L, Olsen JH. Risk of suicide in users of betaadrenoceptor blockers, calcium channel blockers and angiotensin converting enzyme inhibitors. Br J Clin Pharmacol 2001; 52: 313-8.

89 Callréus T, Agerskov Andersen U, Hallas J, Andersen M. Cardiovascular drugs and the risk of suicide: a nested case-control study. Eur J Clin Pharmacol 2006; 63: 591-6.

90 Evon DM, Verma A, Dougherty KA, Batey B, Russo M, Zacks S, et al. High deferral rates and poorer treatment outcomes for HCV patients with psychiatric and substance use comorbidities. Dig Dis Sci 2007; 52: 3251-8.

91 Cradock-O'Leary J, Young AS, Yano EM, Wang M, Lee ML. Use of general medical services by VA patients with psychiatric disorders. Psychiatr Serv 2002; 53: 874-8.

92 Dickerson FB, McNary SW, Brown CH, Kreyenbuhl J, Goldberg RW, Dixon LB. Somatic healthcare utilization among adults with serious mental illness who are receiving community psychiatric services. Med Care 2003; 41: 560-70.
93 Folsom DP, McCahill M, Bartels SJ, Lindamer LA, Ganiats TG, Jeste DV. Medical comorbidity and receipt of medical care by older homeless people with schizophrenia or depression. Psychiatr Serv 2002; 53: 1456-60.

94 Salsberry PJ, Chipps E, Kennedy C. Use of general medical services among medicaid patients with severe and persistent mental illness. Psychiatr Serv 2005; 56: 458-62.

95 Crews $\mathrm{C}$, Batal H, Elasy T, Casper E, Mehler PS. Primary care for those with severe and persistent mental illness. West J Med 1998; 169: 245-50.

96 Drapalski AL, Milford J, Goldberg RW, Brown CH, Dixon LB, et al. Perceived barriers to medical care and mental health care among veterans with serious mental illness. Psychiatr Serv 2008; 59: 921-4.

97 Bradford DW, Kim MM, Braxton LE, Marx CE, Butterfield M, Elbogen EB. Access to medical care among persons with psychotic and major affective disorders. Psychiatr Serv 2008; 59: 847-52.

98 Druss BG, Rosenheck RA. Mental disorders and access to medical care in the United States. Am J Psychiatry 1998; 155: 1775-7.

99 O'Day B, Killeen MB, Sutton J, Iezzoni LI. Primary care experiences of people with psychiatric disabilities: barriers to care and potential solutions. Psychiatr Rehabil J 2005; 28: 339-45.

100 Rice C, Duncan, DF. Alcohol use and reported physician visits in older adults. Prev Med 1995; 24: 229-34.

101 Chwastiak LA, Rosenheck RA, Kazis LE. Utilization of primary care by veterans with psychiatric illness in the national department of veterans affairs health care system. J Gen Int Med 2008; 23: 1835-40.

102 Druss BG, von Esenwein SA. Improving general medical care for persons with mental and addictive disorders: systematic review. Gen Hosp Psychiatry 2006; 28: 145-53.

103 Balfour L, Kowal J, Silverman A, Tasca GA, Angel JB, Macpherson PA, et al. $A$ randomized controlled psycho-education intervention trial: improving psychological readiness for successful HIV medication adherence and reducing depression before initiating HAART. AIDS Care 2006; 18: 830-8.

104 Ismail K, Winkley K, Rabe-Hesketh S. Systematic review and meta-analysis of randomised controlled trials of psychological interventions to improve glycaemic control in patients with type 2 diabetes. Lancet 2004; 363: 1589-97.

105 Winkley K, Landau S, Eisler I, Ismail K. Psychological interventions to improve glycaemic control in patients with type 1 diabetes: systematic review and meta-analysis of randomised controlled trials. BMJ 2006; 333: 65.

106 Anderson LA, Janes GR, Jenkins C. Implementing preventive services: to what extent can we change provider performance in ambulatory care? A review of the screening, immunization, and counseling literature. Ann Behav Med 1998; 20: 161-7.

107 Friedman LC, Neff NE, Webb JA, Latham CK. Early breast cancer detection behaviors among ethnically diverse low-income women. Psychooncology 1996; 5: 283-9.

108 Dodendorf DM, Deogun GK, Rodie AR, Pol LG. Assessing the patient's mammogram experience. Health Care Manage Rev 2004; 29: 77-87.

109 Friedman LC, Moore A, Webb JA, Puryear L. Breast cancer screening among ethnically diverse low-income women in a general hospital psychiatry clinic. Gen Hosp Psychiatry 1999; 21: 374-81.

110 Friedman L, Puryear L, Moore A, Green CE. Breast and colorectal cancer screening among low income women with psychiatric disorders. Psychooncology 2005; 14: 786-91.

111 Phelan M, Stradins L, Morrison S. Physical health of people with severe mental illness. BMJ 2001; 322: 443-4.

112 Arean PA, Ayalon L, Jin C, McCulloch CE, Linkins K, Chen H, et al. Integrated speciality mental health care among older minorities improves access but not outcomes: results of the PRISMe study. Int J Geriatr Psychiatry 2008; 23: 1086-92.

113 Dickinson LM, Dickinson WP, Rost K, DeGruy F, Emsermann C, Froshaug D, et al. Clinician burden and depression treatment: disentangling patient- and clinician-level effects of medical comorbidity. J Gen Intern Med 2008; 23: 1763-9. 